\title{
IMPLEMENTASI TRANSFORMASI WAVELET DAUBECHIES PADA KOMPRESI CITRA DIGITAL
}

\author{
Suma'inna ${ }^{1}$ dan Gugun Gumilar ${ }^{2}$ \\ 1,2 Program Studi Matematika Fakultas Sains dan Teknologi UIN Syarif Hidayatulallah Jakarta
}

\begin{abstract}
ABSTRAK
Proses kompresi merupakan proses mereduksi ukuran suatu data untuk menghasilkan representasi digital yang padat atau mampat, namun tetap dapat mewakili kuantitas informasi yang terkandung pada data tersebut. Pada citra, video, dan suara, kompresi mengarah pada minimalisasi jumlah bit untuk representasi citra digital. Dalam penelitian ini, proses kompresi citra menggunakan dua wavelet yang terkenal, yaitu wavelet Haar dan Daubechies Db4. Citra yang digunakan terbatas hanya citra grayscale berformat.jpg. Tujuan dari penelitian ini adalah menentukan wavelet manakah yang baik dalam kompresi citra. Dari hasil yang didapat, wavelet Haar dan Daubechies Db4 berturut-turut mempunyai nilai RMSE sebesar 6,54 dan 6,5. Sedangkan rasio kompresi untuk wavelet Haar adalah 25\%, lebih besar dibanding wavelet Daubchies Db4, yaitu sebesar $22 \%$.
\end{abstract}

Kata Kunci : Kompresi, wavelet Haar, wavelet Daubchies Db4, RMSE

\section{PENDAHULUAN}

Teknologi kompresi data berkembang seiring dengan kemajuan teknologi informasi. Melalui teknologi kompresi ini, penyebaran data menjadi lebih cepat karena ukuran data yang lebih kecil dari ukuran aslinya, sehingga mempermudah proses pengiriman data atau dapat mengurangi kebutuhan terhadap kapasitas media penyimpanan. Salah satu teknik kompresi citra ialah dengan transformasi wavelet.

Transformasi adalah proses pengubahan data atau sinyal ke dalam bentuk lain agar lebih mudah dianalisis. Transformasi wavelet memiliki kemampuan untuk menganalisis suatu data dalam domain waktu dan domain frekuensi secara simultan. Kompresi berbasis wavelet didasari pada prinsip bahwa koefisien-koefisien hasil proses transformasi wavelet yang melakukan dekorelasi pixel pada citra, dapat dikodekan lebih efisien dibandingkan dengan citra aslinya [1].

Aplikasi dari Wavelet semakin meluas untuk berbagai macam bidang seperti teknik penyelesaian persamaan differensial [2], pemrosesan sinyal dan analisis high dimentional data statistic [3-7]. Dalam proses perhitungan matematis, wavelet dapat menganalisa frekuensi dan waktu secara simultan. Sedangkan dalam sudut pandang fisika wavelet adalah teknik matematika yang digunakan untuk membagi atau memisah sinyal ke dalam komponen-komponen frekuensi yang berbeda dengan menggunakan sebuah penyaring (filterisasi) dengan menggunakan metode Discrete Wavelet Transform (DWT), sehingga setiap komponen dapat diperiksa atau dipelajari pencocokan resolusinya.
DWT yang cukup populer dalam pemerosesan citra adalah DWT Haar (db1) dan Daubechies (db). Transformasi wavelet Daubechies ini telah muncul sebagai salah satu ujung tombak teknologi, dalam bidang sinyal \& analisis citra. Daubechies $(1988,1992)$ mengembangkan teori dan kontruksi wavelet wavelet ortonormal yang mempunyai compact support. Fungsi-fungsi yang mempunyai compact support mempunyai sifatsifat yang menarik, seperti dilasi dan penskalaan.

Pada penelitian ini, mencoba membandingkan dua tipe wavelet yang terkenal, yaitu Daubechies (db2) dan Haar (db1). Dari kedua wavelet tersebut, manakah yang mampu memberikan hasil yang optimum dalam proses kompresi citra digital. Hasil penelitian ini dapat menjadi masukan bagi peneliti lain dalam menentukan wavelet manakah yang optimum dalam memampatkan data selain data citra.

\section{LANDASAN TEORI}

\section{A. Transformasi Wavelet}

Transformasi wavelet memberikan representasi frekuensi-waktu pada sebuah sinyal. Pada awalnya, transformasi wavelet digunakan untuk menganalisa sinyal non-stasioner. Pada transformasi wavelet, sinyal non-stasioner dianalisis menggunakan analisis multi-resolusi. Umumnya, teknik analisis multi-resolusi adalah teknik yang digunakan untuk menganalisis frekuensi yang berbeda menggunakan resolusi yang berbeda [8].

Analisis multiresolusi berisi keluarga subruang tertutup $\left\{V_{m}, m \in \mathbb{Z}\right\}$ dari $L^{2}(R)$ yang memenuhi: 
1. $V_{m} \subset V_{m+1}$, untuk setiap $m \in \mathbb{Z}$.

2. $f(x) \in V_{m}$ jika dan hanya jika $f(2 x) \in V_{m+1}$.

3. $\bigcap_{m \in \mathbb{Z}} V_{m}=\{0\}$

4. $\cup_{m \in Z} V_{m}=L^{2}(R)$

5. Terdapat fungsi skala $\phi(x)$ sedemikian sehingga $\left\{\phi_{0, n}=\phi(x-n), n \in \mathbb{Z}\right\}$ merupakan basis ortonormal untuk $V_{0}$. Untuk $m \rightarrow \infty$, $V_{\infty}=L^{2}$ dan untuk $m \rightarrow-\infty=\{0\}$ [9].

\section{B. Wavelet Haar}

Definisi Fungsi Scala wavelet Haar (Father Wavelet) adalah [8]:

$$
\phi(x)= \begin{cases}1, & \text { jika } 0 \leq x \leq 1 \\ 0, & \text { untuk } x \text { yang lain }\end{cases}
$$

Misal $V_{m}$ adalah ruang fungsi di $L^{2}(R)$ yang konstan pada interval $\left[2^{-m} n, 2^{-m}(n+1)\right], k \in Z$, maka $\left\{V_{m}: m \in Z\right\}$ adalah sebuah analisis multiresolusi yang bersesuaian dengan wavelet Haar. Wavelet Haar yang dikontruksi dari analisis multi-resolusinya diperoleh dari mengeneralisir (mendilasi atau menggeser) fungsi skala (father wavelet) $\phi(x)=\chi_{[0,1)}(x)$ yang bersesuaian dengan MRA. Wavelet Haar memenuhi persamaan dilasi (2.6), dimana

$$
C_{n}=\sqrt{2} \int_{-\infty}^{\infty} \phi(x) \phi(2 x-n) d x .
$$

Dengan demikian diperoleh $C_{0}=C_{1}=\frac{1}{\sqrt{2}}$ dan $C_{n}=0, n \neq 0,1$.

Untuk wavelet Haar atau dikenal juga Daubechies $1(\mathrm{db} 1)$ dengan koefisien $C_{0}=C_{1}=$ $\frac{1}{\sqrt{2}}$ merupakan high pass filter [8].

\section{Wavelet Daubechies}

Wavelet Daubechies adalah pengembangan dari wavelet Haar. Daubechies 1 (db1) dengan panjang filter 2 merupakan wavelet Haar. Daubechies 2 disingkat (db2) adalah wavelet Daubechies dengan banyak filter 4 yang db3 adalah wavelet Daubechies dengan banyak filter 6 dan seterusnya. Selengkapnya koefisien filter sampai db5 dapat dilihat pada tabel 4.1.

\section{Transformasi Wavelet Diskrit}

Transformasi wavelet diskrit (TWD) merupakan pentransformasian sinyal diskrit menjadi koefisien-koefisien wavelet yang diperoleh dengan cara menapis sinyal menggunakan dua buah tapis yang berlawanan low pass filter dan high pass filter. Secara garis besar proses dalam teknik ini adalah dengan melewatkan sinyal yang akan dianalisis pada filter dengan frekuensi dan skala yang berbeda.
Analisis frekuensi yang berbeda dengan menggunakan resolusi yang berbeda inilah yang disebut dengan multi-resolution analysis. Pembagian sinyal menjadi frekuensi tinggi dan frekuensi rendah dalam proses filterisasi highpass filter dan lowpass filter disebut sebagai dekomposisi [10].

Tabel 1. Filter Wavelet Daubechies

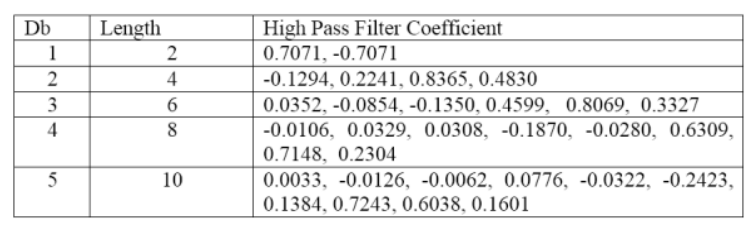

Proses dekomposisi citra yang dimulai dengan melakukan dekomposisi melalui terhadap baris dari data citra, kemudian dilanjutkan dengan dekomposisi terhadap kolom (down sampling), seperti ditunjukkan pada Gambar 1.

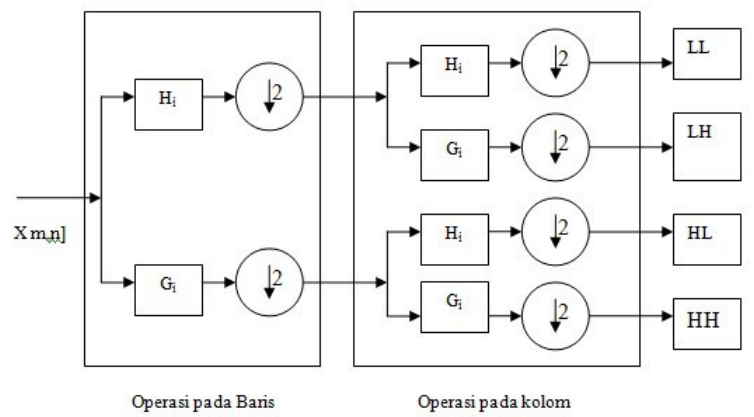

Gambar 1. Transformasi Wavelet Citra Level 1

Komponen LL disebut komponen aproksimasi sementara komponen LH, HL, dan HH disebut komponen detil. Dekomposisi pada transformasi wavelet untuk level 2, 3, dan seterusnya dilakukan dengan cara yang sama, hanya saja dilakukan pada bagian LL.

\section{KOMPRESI CITRA MENGGUNAKAN TRANSFORMASI WAVELET}

Proses kompresi merupakan proses mereduksi ukuran suatu data untuk menghasilkan representasi digital yang padat atau mampat, namun tetap dapat mewakili kuantitas informasi yang terkandung pada data tersebut. Pada citra, video, dan suara, kompresi mengarah pada minimalisasi jumlah bit untuk representasi citra digital.

Transformasi wavelet pada penelitian ini digunakan untuk mengompres matriks gambar dengan melewatkamya pada low pass filter dan high pass filter untuk mendapatkan aproksimasinya. Kompresi gambar menggunakan DWT dikaitkan dengan dekomposisi gambar. Dekomposisi gambar seperti yang ditunjukkan pada Gambar 2 menghasilkan rentang informasi 
frekuensi yang berbeda yaitu LL, frekuensi rendah - rendah, LH, frekuensi rendah - tinggi, HL, frekuensi tinggi - rendah, dan $\mathrm{HH}$, frekuensi tinggi - tinggi [11].

\begin{tabular}{|c|c|c|}
\hline LL2 & HL2 & \multirow{2}{*}{ HL1 } \\
\cline { 1 - 2 } LH2 & HH2 & \\
\cline { 1 - 1 } LH1 & \multirow{2}{*}{ HH1 } \\
\hline
\end{tabular}

Gambar 2. Two Levels Pyramid Decomposition

Tujuan utama kompresi citra adalah untuk mengurangi data berlebihan (redundancy data), sehingga ukuran data menjadi lebih kecil dan lebih ringan dalam proses transmisi data. Setelah image ditansformasi wavelet, tahapan selanjutnya dalam compresi citra adalah kuantisasi. Kuantisasi adalah suatu metode yang bekerja dengan cara mengurangi derajat keabuan, sehingga jumlah bit yang dibutuhkan untuk merepresentasikan citra berkurang. Prosesnya adalah dengan melakukan pengalian dengan koefisien komponen detil dari citra yang sudah ditransformasi dengan wavelet. Nilai koefisiennya dikalikan dengan suatu konstanta pengali yang berkisar antara 0-1 dengan menggunakan rumus berikut [12].

$$
\text { koef } 2=\text { koef } 1 \times \text { konst.pengali } \times \frac{1}{2^{j}}
$$

Dimana :

- $\quad$ koef 2 adalah nilai koefisien komponen detil setelah dikuantisasi

- $\quad$ koef 1 adalah nilai koefisien komponen detil sebelum dikuantisasi

- $\quad j$ adalah level dekomposisi

Pengalian dengan 0 (nol) akan menghasilkan rasio kompresi yang paling besar. Tetapi akibatnya akan menghasilkan gambar kompresi yang buruk, karena semua informasi dari komponen detil dihilangkan. Sedangkan pengalian dengan 1 (satu) akan mengahasilkan gambar kompresi yang sangat baik. Tetapi dalam hal ini bukan merupakan sistem pengkompresian, karena tidak ada proses kuantisasi. Oleh karena itu koefisien komponen detil dikalikan dengan konstanta pengali dari antara 0 dan 1 [12].

Tahapam-tahapan yang dilakukan dapat dilihat pada flowchart di bawah ini:

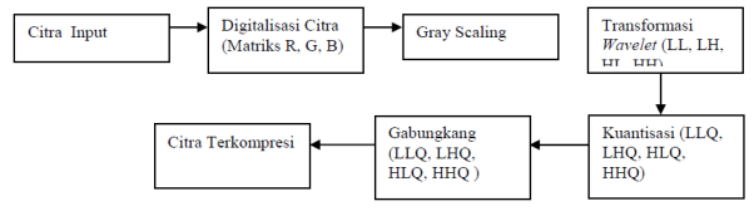

Gambar 3. Flowchart Tahapan Kompresi dan Dekompresi

\section{A. Kualitas Kompresi Citra (fidelity)}

Kualitas citra hasil kompresi dapat diukur secara kuantitatif dengan melihat nilai Root Mean Square Error (RMSE)

$$
R M S E=\sqrt{\frac{1}{M \times N} \sum_{x=1}^{M} \sum_{y=1}^{N}(\hat{f}(x, y)-f(x, y))^{2}}
$$

Dan Peak Signal to Noise Ratio (PSNR)

$$
P S N R=20 \times \log _{10}\left(\frac{\operatorname{maks} \hat{f}(x, y)}{R M S E}\right)
$$

Dalam hal ini $\hat{f}(x, y)$ dan $f(x, y)$ berturutturut merupakan fungsi dari citra hasil kompresi dan fungsi dari citra asli, sedangkan maks adalah nilai intensitas terbesar. Semakin besar nilai PSNR, maka citra hasil pemampatan semakin mendekati citra aslinya, dengan kata lain semakin bagus kualitas citra hasil kompresi tersebut [13]. Untuk lossy compression, nilai PSNR yang baik berkisar antara 30 dan $50 \mathrm{~dB}$.

\section{B. Rasio Kompresi Citra}

Rasio kompresi citra adalah ukuran persentase citra yang telah berhasil dimampatkan. Secara matematis, rasio pemampatan citra dituliskan sebagai berikut [13]:

$$
\text { Rasio }=100 \%-\left[\frac{\hat{a}}{a} x 100 \%\right]
$$

Keterangan :

$\hat{a}=$ hasil kompresi (bit)

$a=$ citra asli (bit)

\section{Proses Dekompresi}

Proses dekompresi ini adalah proses untuk mengembalikan citra pada ukuran semula melalui kuantisasi balik dekuantisasi dan transformasi balik (invers) wavelet. Untuk melakukan proses kuantisasi balik (dekuantisasi) untuk mengembalikan data yang sebelumnya di kuantisasi saat proses kompresi. 
Proses ini akan memperoleh kembali komponen-komponen detil, yaitu horizontal, vertikal, dan diagonal dengan menggunakan rumus.

$$
\text { koef } 1=\frac{\text { koef } 2 \times 2^{j}}{\text { konst.pengali }}
$$

Sebelum melakukan transformasi wavelet balik, terlebih dahulu menggabungkan seluruh komponen hasil dekuantisasi dengan komponen aproksimasi kemudian dilakukan invers transformasi.

\section{PEMBAHASAN}

Citra yang digunakan dalam penelitian ini adalah tiga buah citra yang diperoleh dari kamera handphone dengan resolusi 3.2 MP. Citra tersebut diberi nama citra ukiran, patung, dan pura gambar 4. Masing-masing berukuran 256 x 256 piksel.
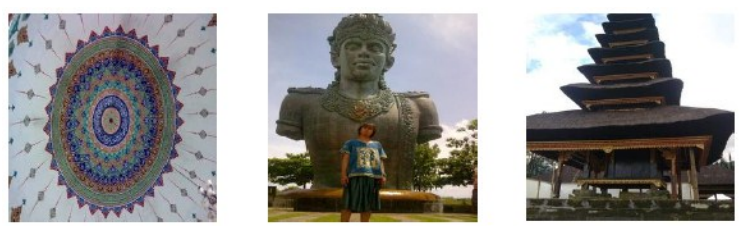

Gambar 4. Data Citra

\section{A. Transformasi Wavelet Maju}

Pada tahap ini, citra pada Gambar 4. ditransformasi dengan menggunakan transformasi wavelet Haar dan Daubechies Db4 satu level. Pada Gambar 5a proses transformasi dilakukan 1 kali (1 level) dekomposisi.

\section{B. Kuantisasi Komponen Detil}

Hasil dari transformasi wavelet Haar dan Daubechies Db4 1 level adalah 4 buah komponen matrik citra, yaitu komponen aproksimasi (LL), komponen horizontal (LH), komponen diagonal $(\mathrm{HH})$, dan komponen vertikal (HL). Komponen aproksimasi (LL) disimpan ke dalam media penyimpanan agar komponen ini tidak berubah. Sedangkan untuk komponen komponen detil dilakukan kuantisasi, Pemilihan konstanta pengali dilakukan berdasarkan variansi dari ketiga komponen detil tersebut. Komponen yang mempunyai variansi yang paling besar dikalikan dengan konstanta yang paling besar pula dan sebaliknya. Dalam penelitian ini digunakan konstanta pengali sebesar $0.5,0.6$, dan 0.4. Ukuran komponen detil setelah proses kuantisasi dapat dilihat pada tabel 2 .
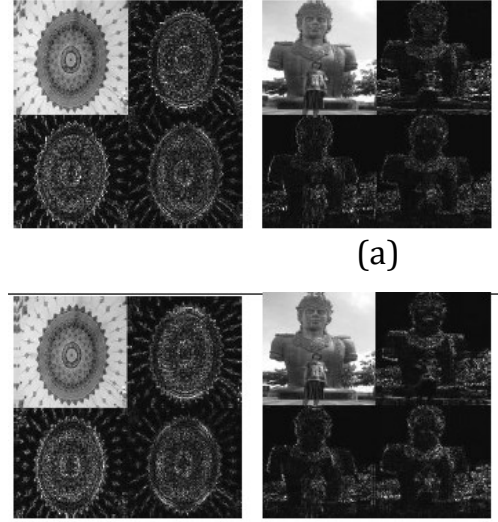

(b)

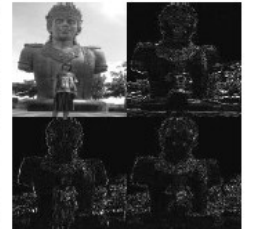

(a)

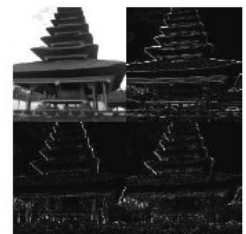

Gambar 5. (a) Transformasi Wavelet Haar 1 Level (b) Transformasi Wavelet Daubechies Db4 1 Level

Tabel 2 Ukuran Komponen detil sebelum dan setelah dikuantisasi

\begin{tabular}{|c|c|c|c|c|c|}
\hline \multirow{4}{*}{ Citra } & \multirow{2}{*}{$\begin{array}{c}\text { Komponen } \\
\text { detil }\end{array}$} & \multicolumn{4}{|c|}{ Size (bytes) } \\
\cline { 3 - 6 } & & $\begin{array}{c}\text { Sebelum Kuantisasi } \\
\text { Waar }\end{array}$ & $\begin{array}{l}\text { Wavelet } \\
\text { Daubechies } \\
\text { Db4 }\end{array}$ & $\begin{array}{c}\text { Wavelet } \\
\text { Haar }\end{array}$ & $\begin{array}{l}\text { Wavelet } \\
\text { Daubechies } \\
\text { Db4 }\end{array}$ \\
\hline \multirow{3}{*}{ Ukiran } & Horizontal & 5.777 & 5.808 & 2.381 & 2.464 \\
\cline { 2 - 6 } & Vertical & 6.203 & 6.463 & 3.091 & 3.127 \\
\cline { 2 - 6 } & Diagonal & 5.240 & 5.078 & 1.800 & 1.772 \\
\hline \multirow{3}{*}{ Patung } & Horizontal & 3.666 & 3.759 & 1.763 & 1.627 \\
\cline { 2 - 6 } & Vertical & 3.311 & 3.357 & 1.380 & 1.275 \\
\cline { 2 - 6 } & Diagonal & 2.938 & 3.544 & 1.078 & 1.701 \\
\hline \multirow{3}{*}{ Pura } & Horizontal & 3.656 & 3.660 & 1.893 & 1.822 \\
\cline { 2 - 6 } & Vertical & 2.936 & 3.109 & 1.316 & 1.371 \\
\cline { 2 - 6 } & Diagonal & 2.972 & 3.157 & 1.114 & 1.166 \\
\hline
\end{tabular}

Dari Tabel 2 dapat diketahui bahwa rasio kompresi citra dengan wavelet Haar lebih tinggi dibanding wavelet Daubechies Db4.

\section{Dekompresi (rekonstruksi) Citra}

Untuk mengembalikan citra terkompresi ke citra semula adalah dengan melakukan dekantisasi dan invers tyransformasi wavelet. Hasil dari transformasi wavelet balik dapat dilihat pada Gambar 5b.

Komponen detil hasil proses dekuantisasi akan berbeda dengan komponen detil sebelum kuantisasi. Hal ini terjadi karena pada saat proses kuantisasi terjadi pembulatan ke bilangan terdekat. Sehingga ketika komponen detil didekuantisasi, hasilnya tidak sama persis dengan komponen detil sebelum kuantisasi. Walaupun demikian, citra hasil transformasi wavelet balik pada Gambar 6a apabila dibandingkan dengan citra asli pada Gambar 4, maka terlihat tidak ada perbedaan yang signifikan antara citra asli dengan citra rekonstruksi. 


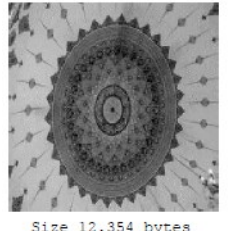

size 12.354 bytes
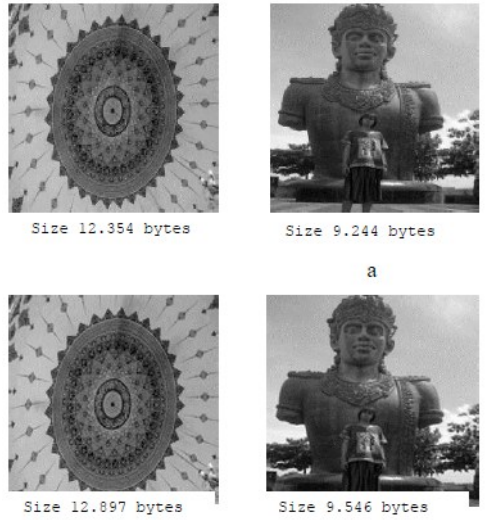

Size 9.244 bytes

a

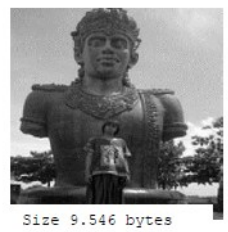

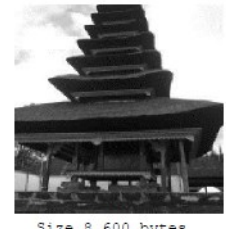

size 8.600 bytes

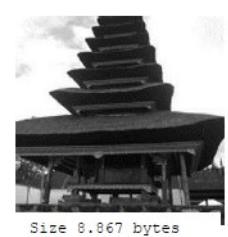

Size 8.867 bytes
Gambar 6 Transformasi Wavelet Balik (a) Wavelet Haar (b) Wavelet Daubechies Db4

\section{REFERENSI}

[1] Sonja Grgic, Mislav Grgic, and Branka ZovkoCihlar Performance Analysis of Image Compression Using Wavelets IEEE Transactions On Industrial Electronics, Vol. 48, No. 3, June 2001, $682-695$

[2] Dahmen, Wolfgang c.s., "Multiscale Wavelet Method for Partial differensial equations", Academic Pres, 1997.

[3] Mallat, Stephanie, "A Wavelet Tour of Signal Processing, 2nd edition, Academic Press, 1999.

[4] Rafiee, J c.s., "Wavelet Basis Functions In Biomedical Signal Processing", J. Rafiee cs. 2011, Expert System with Applications 38, 2011, 6190-6201.
[5] Zhang, Xiaoqun c.s., "Wavelet Inpainting By Nonlocal Total Variation", Inverse Problems and Imaging, Volume 4, No. 1, 2010, 191-210.

[6] Varletti, Martin c.s., "Fourier and Wavelet Signal Processing”, Copyright (c) 2011 by copyright under the AttributionNonCommercial-NoDerivs 3.0 Unported License from Creative Commons.

[7] Ergun Gumus dkk, "Evaluation of Face recognition Techniques using PCA, Wavelet and SVM ", Journal of Expert Systrem With Application 37, 2010, (6404 - 6408), Elsivier.

[8] E. Hernandez and G. Weis, A First Course on Wavelets, CRC Press, New York, 1996.

[9] Lokenath Debnath, Wavelet Transform and their Applications, Birkhäuser, Boston-BaselBerlin, 2002.

[10]Terzija, Nataša, Robust Digital Image Watermarking Algorithms for Copyright Protection. Universität Duisburg- Essen, 2006

[11] Graps, Amara, An Introduction to Wavelet, Institute of Electrical Electronics Engineers, 1995.

[12] Gonzalez RC et al, Digital Image Processing Using Matlab. New Jersey: Pearson Prentice Hall, 2002.

[13]Sutoyo, T, dkk. 2009, "Teori Pengolahan Citra Digital”, Penerbit Andi. Yogyakarta hal 9 - 27. 